\title{
Transactions
}

Cite this: Dalton Trans., 2011, 40, 2757

\section{2,3-Bis(1-methylimidazol-2-yl)quinoxaline (bmiq), a new ligand with decoupled electron transfer and metal coordination sites: the very different redox behaviour of isoelectronic complexes with $\left[\mathrm{PtCl}_{2}\right]$ and $\left[\mathrm{AuCl}_{2}\right]^{+} \uparrow$}

\author{
Ece Bulak, ${ }^{a}$ Tereza Varnali, ${ }^{b}$ Brigitte Schwederski, ${ }^{a}$ Biprajit Sarkar, ${ }^{a}$ Ingo Hartenbach, ${ }^{a}$ Jan Fiedler ${ }^{c}$ and \\ Wolfgang Kaim*a
}

Received 24th September 2010, Accepted 9th December 2010

DOI: $10.1039 / \mathrm{codt01282c}$

\begin{abstract}
The new, potentially ambidentate heterocyclic ligand 2,3-bis(1-methylimidazol-2-yl)quinoxaline (bmiq) was obtained from 2,3-bis(1-methylimidazol-2-yl)glyoxal and 1,2-diaminobenzene. Its coordination to $\mathrm{PtCl}_{2}$ and to the isoelectronic $\left[\mathrm{AuCl}_{2}\right]^{+}$in $\left[\mathrm{AuCl}_{2}(\mathrm{bmiq})\right]\left(\mathrm{AuCl}_{4}\right)$ occurs via the imine $\mathrm{N}$ donors of the imidazolyl groups, leading to the formation of seven-membered chelate rings with boat conformation. According to the spectroelectrochemistry (UV-vis-NIR, EPR), the reversible electron addition to the $\left[\mathrm{PtCl}_{2}\right.$ (bmiq)] and the free ligand takes place in the (non-coordinated) quinoxaline part of the molecule, similarly as for related complexes of dipyrido[3,2-a:2',3'-c]phenazines (dppz), 2,3-bis(2-pyridyl)quinoxalines (bpq) and 2,3-bis(dialkylphosphino)quinoxalines (QuinoxP). DFT calculations confirm the experimental results (structures, spectroscopy) and also point to the coordination potential of the quinoxaline $\mathrm{N}$ atoms. The electron addition to $\left[\mathrm{AuCl}_{2}(\mathrm{bmiq})\right]^{+}$takes place not at the ligand but at the metal site, according to experimental and DFT results.
\end{abstract}

\section{Introduction}

The coordination compounds of ligands in which the metal binding location and the electron transfer site are spatially and electronically separated have raised attention in various areas. The molecule dipyrido[3,2-a:2', $\left.3^{\prime}-c\right]$ phenazine (dppz, Scheme 1) and its many derivatives were thus shown by various techniques to exhibit such a situation ${ }^{1}$ and the ability of certain complexes of dppz to exhibit environmentally and, especially, intercalation dependent luminescence made them popular as "molecular light switches". 2 Specifically, the chelate coordination to form a five-membered ring

IInstitut für Anorganische Chemie, Universität Stuttgart, Pfaffenwaldring 55,D-70550 Stuttgart, Germany.E-mail: kaim@iac.uni-stuttgart.de ${ }^{b}$ Chemistry Department, Bogazici University, Bebek, Istanbul 34342, Turkey ${ }^{c} J$. Heyrovsky Institute of Physical Chemistry, v.v.i., Academy of Sciences of the Czech Republic, Dolejskova 3, CZ-18223 Prague, Czech Republic

$\dagger$ CCDC reference numbers 792125-792127. For crystallographic data in CIF or other electronic format see DOI: $10.1039 / \mathrm{c} 0 \mathrm{dt} 01282 \mathrm{c}$ occurs at the $\alpha$-diimine site of the 1,10-phenanthroline part of the molecule, whereas the rather facile electron addition takes place mainly in the quinoxaline moiety. ${ }^{\text {a }}$

The 2,3-bis(dialkylphosphino)quinoxaline ligands (QuinoxP, Scheme 1), although developed for the purpose of stereoselective organic catalysis with an oxidatively stable diphosphine, ${ }^{3}$ were shown to exhibit a similar separation of chelate coordination activity (at the diphosphine site) and electron transfer (at the quinoxaline heterocycle). ${ }^{4}$

A related type of ligand is based on the commercially available 2,3-bis(2-pyridyl)quinoxaline (dpq). ${ }^{5}$

We have now obtained another such system, 2,3-bis(1methylimidazol-2-yl)quinoxaline (bmiq, Scheme 2), by reacting 1,2-diaminobenzene (o-phenylenediamine) with the known 2,3bis(1-methylimidazol-2-yl)glyoxal. ${ }^{6}$

In addition to using the biorelevant imidazole substituents, reminiscent of the histidine side chain, ${ }^{7,8}$ we were interested in probing the possibility of chelation via both imidazol-2-yl imine

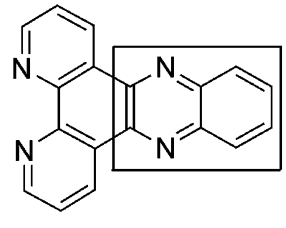

dppz

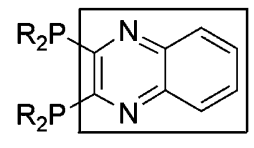

QuinoxP ( $R=$ alkyl)

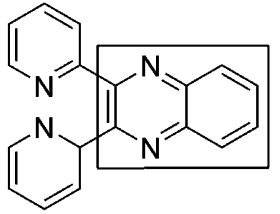

$\mathrm{dpq}$

Scheme 1 


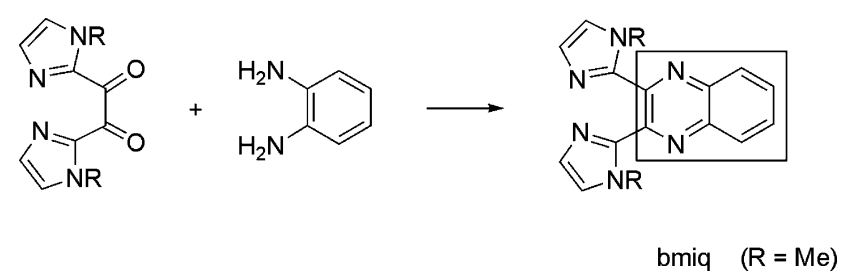

Scheme 2

$\mathrm{N}$ donors to form a seven-membered chelate ring (A, Scheme 3) or via one imidazol-2-yl imine $\mathrm{N}$ and one quinoxaline $\mathrm{N}$ to result in a perhaps stabilized five-membered chelate ring situation (B, Scheme 3). Using the $\left[\mathrm{PtCl}_{2}\right]$ complex fragment, which was employed before for QuinoxP $\mathrm{P}^{4}$ and $\mathrm{dpq}^{5 \mathrm{~b}, \mathrm{c}}$ and the isoelectronic $\left[\mathrm{AuCl}_{2}\right]^{+}$we report here the synthesis, and the structural, spectroscopic and spectroelectrochemical characterisation of the bmiq ligand and its $\mathrm{PtCl}_{2}$ and $\left[\mathrm{AuCl}_{2}\right]^{+}$complexes, as well as DFT calculations of these species and of their one-electron reduced forms.

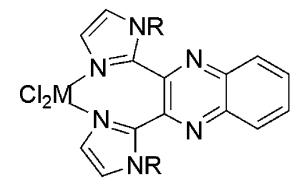

A

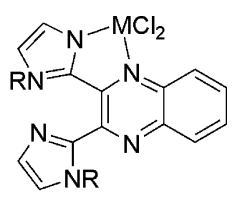

B

\section{Scheme 3}

Platinum(II) complexes have been studied widely because they can exhibit a large range of special properties: some of them are being successfully applied as cytostatica in the therapy of tumours, ${ }^{9}$ they frequently emit in the solution and in the solid state, ${ }^{10}$ their physical properties can be very sensitive towards the environment (solvatochromism, thermochromism, vapochromism, ionochromism), ${ }^{11}$ they may be used as precursor or supporting materials in the conversion of solar energy, ${ }^{12}$ they can aggregate via $\sigma / \sigma$ or $\pi / \pi$ interactions (e.g. stacking), their crystallisation variants often exhibit different physical characteristics, ${ }^{13}$ they can be electrochemically active if coordinated to a non-innocent ligand, ${ }^{14}$ the inert bonds can be employed for studies of reaction mechanisms, ${ }^{15}$ they can be converted to efficiently $\mathrm{C}-\mathrm{H}$ activating catalysts $^{16}$ and they may serve as structure maintaining vertices of large supramolecular frameworks. ${ }^{17}$ Although isoelectronic to $\mathrm{PtCl}_{2}$, the $\left[\mathrm{AuCl}_{2}\right]^{+}$analogue is clearly more reducible, i.e. distinguished by lower lying unoccupied MOs. This study will illustrate the differences between the corresponding complexes with the new bmiq $\pi$ acceptor ligand.

\section{Experimental}

\section{Instrumentation}

EPR spectra in the $\mathrm{X}$ band $(9.5 \mathrm{GHz})$ were recorded with a Bruker System EMX. UV-vis-NIR absorption spectra were recorded on J\&M TIDAS and Shimadzu UV 3101 PC spectrophotometers. Fluorescence of the samples in solution, as well as in the solid phase, was studied using a Perkin-Elmer LS50B spectrophotometer at room temperature, within the range of 200-800 nm. Cyclic voltammetry was carried out in $0.1 \mathrm{M} \mathrm{Bu}_{4} \mathrm{NPF}_{6}$ solutions using a three-electrode configuration (glassy carbon working electrode, $\mathrm{Pt}$ counter electrode, $\mathrm{Ag} / \mathrm{AgCl}$ reference) and a PAR 273 potentiostat and function generator. The ferrocene/ferrocenium $\left(\mathrm{Fc} / \mathrm{Fc}^{+}\right)$ couple served as internal reference. Spectroelectrochemistry was performed using an optically transparent thin-layer electrode (OTTLE) cell. ${ }^{18 a} \mathrm{~A}$ two-electrode capillary served to generate intermediates for the $\mathrm{X}$ band EPR studies. ${ }^{18 \mathrm{~b}}$

\section{Syntheses}

2,3-Bis(1-methylimidazol-2-yl)quinoxaline (bmiq). The preparation of the ligand was performed using a similar procedure to that of the dipyrrole analogue. ${ }^{19}$ A mixture of $30 \mathrm{mg}(0.137$ $\mathrm{mmol}$ ) of 2,3-bis(1-methylimidazol-2-yl)glyoxal and $39.69 \mathrm{mg}$ $(0.367 \mathrm{mmol})$ of $o$-phenylenediamine was dissolved in $8 \mathrm{~mL}$ of glacial acetic acid and stirred at $90{ }^{\circ} \mathrm{C}$ for $12 \mathrm{~h}$ in the dark under an argon atmosphere. After the removal of the solvent the viscous substance was chromatographed on a silica column where $30.6 \mathrm{mg}$ ( $77 \%$ yield) of pure product could be obtained with ethanol-ethyl acetate $(1: 1)$. Single crystals for X-ray diffraction were obtained from methylene chloride/hexane. Anal. calcd for $\mathrm{C}_{16} \mathrm{H}_{14} \mathrm{~N}_{6}$ (290.33): C 66.19, H 4.86, N 28.95. Found: C 65.39, $\mathrm{H}$ 4.56, N 28.29\%. MS (\%): $313.12\left(100, \mathrm{M}^{+}+\mathrm{Na}\right), 291.13$ $\left(55, \mathrm{M}^{+}+\mathrm{H}\right) .{ }^{1} \mathrm{H}$ NMR (DMSO- $\left.d_{6}\right): 3.74\left(6 \mathrm{H}, \mathrm{s}, \mathrm{CH}_{3}\right), 6.84$ ( $2 \mathrm{H}$, br s, imidazole), $7.26(2 \mathrm{H}$, br s, imidazole $), 7.95(2 \mathrm{H}, \mathrm{m}$, quinoxaline), 8.17 (2H, m, quinoxaline). ${ }^{1} \mathrm{H} \mathrm{NMR}\left(\mathrm{CD}_{3} \mathrm{CN}\right): 3.81$ $\left(6 \mathrm{H}, \mathrm{s}, \mathrm{CH}_{3}\right), 6.89$ (2H, s, imidazole), $7.12(2 \mathrm{H}, \mathrm{s}$, imidazole), 7.93 (2H, m, quinoxaline), $8.14\left(2 \mathrm{H}, \mathrm{m}\right.$, quinoxaline). ${ }^{13} \mathrm{C} \mathrm{NMR}$ (DMSO- $d_{6}$ ): $33.97,123.6,127.4,129.12,132.2,139.78,143.86$, 145.64. UV-vis $\left(\mathrm{CH}_{3} \mathrm{CN}\right), \lambda_{\max }(\mathrm{nm})\left[\varepsilon\left(\mathrm{mol} \mathrm{dm} \mathrm{dm}^{-3} \mathrm{~cm}^{-1}\right)\right]: 367$ [10 300], 289 [14 800], 247 [28 250].

[PtCl $\mathbf{2}$ (bmiq)]. To $50.5 \mathrm{mg}$ of bmiq $(0.173 \mathrm{mmol})$ in $15 \mathrm{~mL}$ of acetonitrile was added $0.73 \mathrm{mg}$ of $\left[\mathrm{PtCl}_{2}\left(\mathrm{dmso}_{2}\right](0.173 \mathrm{mmol})\right.$ in $15 \mathrm{~mL} \mathrm{CH}_{3} \mathrm{CN}$. After stirring for $12 \mathrm{~h}$ at $60^{\circ} \mathrm{C}$, the pale yellow solid formed was filtered to give $50 \mathrm{mg}(51.9 \%)$ of product, which gave single-crystal $\mathrm{X}$-ray suitable crystals from nitromethane. Anal. calcd for $\mathrm{C}_{16} \mathrm{H}_{14} \mathrm{Cl}_{2} \mathrm{~N}_{6} \mathrm{Pt}$ (556.32): C 34.54, H 2.54, N 15.11. Found: C 34.38, H 2.30, N 14.44\%. ${ }^{1} \mathrm{H}$ NMR ( $\left.\mathrm{CD}_{3} \mathrm{CN}\right): 3.86\left(6 \mathrm{H}, \mathrm{s}, \mathrm{CH}_{3}\right)$, 7.33 (4H, br s, imidazole), $8.06(2 \mathrm{H}, \mathrm{m}$, quinoxaline $), 8.30(2 \mathrm{H}, \mathrm{m}$, quinoxaline). ${ }^{195} \mathrm{Pt}$ satellite lines could not be observed because of the poor solubility of the complex. This also prevented us from determining exact molar extinction values. $\mathrm{UV}$-vis $\left(\mathrm{CH}_{3} \mathrm{CN}\right), \lambda_{\max }$ (nm): 362, 273, 246.

[AuCl $\mathbf{A}_{\mathbf{2}}$ (bmiq)] $\left[\mathrm{AuCl}_{\mathbf{4}}\right]$. To $38.7 \mathrm{mg}$ of $\mathrm{KAuCl}_{4}(0.1 \mathrm{mmol})$ in $15 \mathrm{~mL}$ of methanol was added $28 \mathrm{mg}$ of bmiq $(0.1 \mathrm{mmol})$ in $15 \mathrm{~mL}$ $\mathrm{CH}_{3} \mathrm{OH}$. After stirring for $4 \mathrm{~h}$ in the dark, the yellow solid that formed was filtered to give $51 \mathrm{mg}(58 \%)$ of product. Single-crystal $\mathrm{X}$-ray suitable crystals were obtained from acetonitrile. Anal. calcd for $\mathrm{C}_{16} \mathrm{H}_{14} \mathrm{Au}_{2} \mathrm{Cl}_{6} \mathrm{~N}_{6}$ (896.97): C 21.43, H 1.57, N 9.37. Found: $\mathrm{C}$ 22.84, H 1.42, N 9.60\%. ${ }^{1} \mathrm{H}$ NMR $\left(\mathrm{CD}_{3} \mathrm{CN}\right): 3.96\left(6 \mathrm{H}, \mathrm{s}, \mathrm{CH}_{3}\right)$, 7.51 ( $2 \mathrm{H}$, br s, imidazole), 7.65 (2H, br s, imidazole), $8.19(2 \mathrm{H}$, $\mathrm{m}$, quinoxaline), $8.35\left(2 \mathrm{H}, \mathrm{m}\right.$, quinoxaline). UV-vVis $\left(\mathrm{CH}_{3} \mathrm{CN}\right)$, $\lambda_{\max }(\mathrm{nm})\left[\varepsilon\left(\mathrm{mol} \mathrm{dm} \mathrm{cm}^{-1}\right)\right.$ ]: $360 \mathrm{sh}, 337$ [8570], 276 [23 070], 250 [26 900].

Crystallography. Single crystals of bmiq, $\left[\mathrm{PtCl}_{2}\right.$ (bmiq)] and $\left[\mathrm{AuCl}_{2}\right.$ (bmiq) $]\left(\mathrm{AuCl}_{4}\right)$ were obtained by slow evaporation from saturated solutions (see above). Data were collected for selected specimens: bmiq, colourless lath $(3.3 \times 1.1 \times 1.0 \mathrm{~mm})$; 
Table 1 Crystallographic data

\begin{tabular}{llll}
\hline & bmiq & {$\left[\mathrm{PtCl}_{2}(\mathrm{bmiq})\right]$} & {$\left[\mathrm{AuCl}_{2}(\mathrm{bmiq})\right]\left(\mathrm{AuCl}_{4}\right)$} \\
\hline empirical formula & $\mathrm{C}_{16} \mathrm{H}_{14} \mathrm{~N}_{6}$ & $\mathrm{C}_{16} \mathrm{H}_{14} \mathrm{Cl}_{2} \mathrm{~N}_{6} \mathrm{Pt}$ & $\mathrm{C}_{16} \mathrm{H}_{14} \mathrm{Au}_{2} \mathrm{Cl}_{6} \mathrm{~N}_{6}$ \\
$\mathrm{FW}$ & 290.33 & 556.32 & 896.97 \\
Space group & $P 2_{1} / n$ & $P 2_{1} / c$ & $P 2_{1} / n$ \\
$a / \AA$ & $9.0875(5)$ & $14.5272(7)$ & $9.7732(2)$ \\
$b / \AA$ & $10.3843(7)$ & $9.5752(4)$ & $24.6103(5)$ \\
$c / \AA$ & $14.7640(8)$ & $13.5829(7)$ & $10.1615(2)$ \\
$\beta /^{\circ}$ & $105.664(3)$ & $101.724(2)$ & $107.0950(10)$ \\
$V / \AA^{3}$ & $1341.50(14)$ & $1849.98(12)$ & $2336.08(8)$ \\
$Z$ & 4 & 4 & 4 \\
$D_{\mathrm{c}} / \mathrm{g} \mathrm{cm}^{-3}$ & 1.438 & 1.997 & 2.550 \\
$\mu / \mathrm{mm}^{-1}$ & 0.09 & 7.89 & 13.25 \\
$R_{\text {int }}$ & 0.105 & 0.044 & 0.047 \\
$R_{1}$ & 0.090 & 0.060 & 0.047 \\
$\mathrm{w} R_{2}$ & 0.163 & 0.110 & 0.071 \\
$\mathrm{GooF}$ & 1.079 & 1.057 & 1.021 \\
largest difference & $0.382 /-0.343$ & $3.143 /-3.196$ & $1.840 /-1.926$ \\
peak/hole/e $\AA^{-3}$ & & & \\
\hline
\end{tabular}

[ $\mathrm{PtCl}_{2}$ (bmiq) $]$, colourless platelet $(0.7 \times 0.6 \times 0.2 \mathrm{~mm})$ and $\left[\mathrm{AuCl}_{2}\right.$ (bmiq) $]\left(\mathrm{AuCl}_{4}\right)$, reddish platelet $(2.2 \times 1.2 \times 0.8 \mathrm{~mm})$. A NONIUS Kappa CCD diffractometer was used at $100 \mathrm{~K}$, additional crystallographic information is given in Table 1. The structures were solved using direct methods with refinement by full-matrix least squares of $F^{2}$, employing the program system SHELXL $97^{20}$ in connection with a numerical absorption correction in case of bmiq and an empirical correction for [ $\mathrm{PtCl}_{2}$ (bmiq)] and $\left[\mathrm{AuCl}_{2}(\mathrm{bmiq})\right]\left(\mathrm{AuCl}_{4}\right)$. All non-hydrogen atoms were refined anisotropically.

\section{DFT calculations}

Density functional theory (DFT) calculations were carried out using the program package GAUSSIAN. ${ }^{21}$ The hybrid functional B3LYP (UB3LYP for radical anions) with the LANL2DZ basis set was employed. ${ }^{6 c}$ The ligand, the complexes and their oneelectron reduced forms were subjected to calculations. Also, $\mathrm{PtCl}_{2}$ complexes yielding a 7-membered (A) and a 5-membered (B) chelate ring were studied (see Scheme 3).

\section{Results and discussion}

\section{Synthesis and structure}

The new heterocycle bmiq has been obtained via a standard synthetic condensation procedure for preparing quinoxalines, ${ }^{19} \mathrm{using}$ the previously introduced ${ }^{6}$ 2,3-bis(1-methylimidazol-2-yl)glyoxal. The compound was characterised by single-crystal X-ray crystal diffraction (Table 1), the molecules in the crystal studied exhibit a pronounced, unsymmetrical twisting between the planes of the quinoxaline $\pi$-acceptor system and the $\pi$ electron donating methylimidazolyl substituents (Fig. 1, Table 2).

The complexation of bmiq with $\mathrm{PtCl}_{2}$ involving the $\left[\mathrm{PtCl}_{2}(\mathrm{dmso})_{2}\right]$ precursor gave a single mononuclear product, $\left[\mathrm{PtCl}_{2}\right.$ (bmiq)], characterised by ${ }^{1} \mathrm{H}$-NMR and single-crystal X-ray crystallography as the symmetrically methylimidazolyl-chelated coordination compound (Fig. 2). The resulting seven-membered ring, involving both imine functions of the imidazoles, is not planar but exhibits a typical ${ }^{6}$ boat conformation (Table 2 ). The dihedral

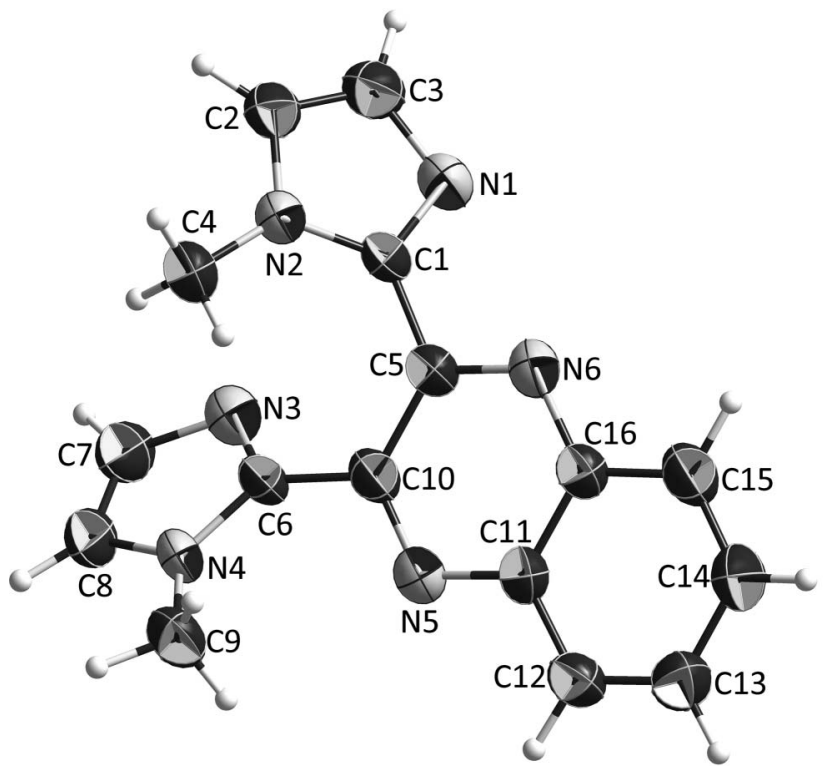

Fig. 1 The molecular structure of bmiq in the crystal (ellipsoid probability: $95 \%)$.

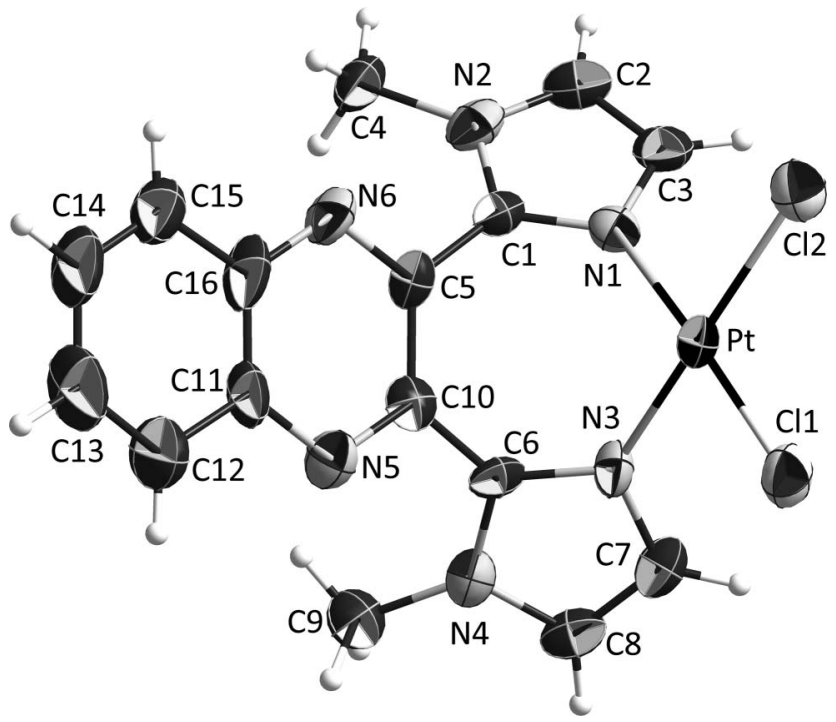

Fig. 2 The molecular structure of $\left[\mathrm{PtCl}_{2}\right.$ (bmiq)] in the crystal (ellipsoid probability: 95\%).

angles between the quinoxaline and the imidazolyl rings amount to about $69^{\circ}$.

A similar chelation and conformation was found for $\left[\mathrm{AuCl}_{2} \text { (bmiq) }\right]^{+}$, which was obtained as the tetrachloroaurate salt from the reaction of bmiq with $\mathrm{KAuCl}_{4}$ (Fig. 3, Table 2).

Significant intermolecular interactions were not observed for the compounds presented here, presumably due to the non-planar molecular structures with severely twisted methylimidazolyl substituents. The structural properties of bmiq and its complexes could be well reproduced by DFT calculations (Table 2). This method suggested a higher energy for the five-membered chelate alternative B (Scheme 3) over the experimentally observed sevenmembered chelate form $\mathbf{A}$ by $12.42 \mathrm{kcal} \mathrm{mol}^{-1}$ in the case of the $\mathrm{PtCl}_{2}$ complex. 
Table 2 Experimental and calculated bond lengths and angles for compounds

\begin{tabular}{|c|c|c|c|c|c|c|c|c|c|}
\hline Bond lengths/Å & bmiq (exp) & bmiq (DFT) & bmiq $^{\cdot-}(\mathrm{DFT})$ & $\begin{array}{l}{\left[\mathrm{PtCl}_{2}(\mathrm{bmiq})\right]} \\
(\exp )\end{array}$ & $\begin{array}{l}{\left[\mathrm{PtCl}_{2}(\mathrm{bmiq})\right]} \\
(\mathrm{DFT})\end{array}$ & $\begin{array}{l}{\left[\mathrm{PtCl}_{2}(\mathrm{bmiq})\right]^{--}} \\
(\mathrm{DFT})\end{array}$ & $\begin{array}{l}{\left[\mathrm{AuCl}_{2}(\mathrm{bmiq})\right]^{+}} \\
(\exp )\end{array}$ & $\begin{array}{l}{\left[\mathrm{AuCl}_{2}(\mathrm{bmiq})\right]^{+}} \\
(\mathrm{DFT})\end{array}$ & $\begin{array}{l}{\left[\mathrm{AuCl}_{2}(\mathrm{bmiq})\right]^{\circ}} \\
(\mathrm{DFT})\end{array}$ \\
\hline $\mathrm{N} 1-\mathrm{C} 1$ & $1.321(3)$ & 1.348 & 1.358 & $1.349(8)$ & 1.355 & 1.360 & $1.332(7)$ & 1.359 & 1.392 \\
\hline $\mathrm{N} 2-\mathrm{C} 1$ & $1.364(3)$ & 1.389 & 1.398 & $1.346(8)$ & 1.385 & 1.387 & $1.353(7)$ & 1.374 & 1.388 \\
\hline N2-C2 & $1.373(3)$ & 1.390 & 1.397 & $1.371(8)$ & 1.391 & 1.396 & $1.374(7)$ & 1.393 & 1.392 \\
\hline C5-C10 & $1.439(3)$ & 1.457 & 1.413 & $1.432(9)$ & 1.457 & 1.418 & $1.421(7)$ & 1.450 & 1.458 \\
\hline C5-N6 & $1.324(3)$ & 1.340 & 1.395 & $1.327(7)$ & 1.341 & 1.379 & $1.322(7)$ & 1.342 & 1.344 \\
\hline $\mathrm{M}-\mathrm{Cl} 2$ & & & & $2.308(2)$ & 2.405 & 2.429 & $2.257(1)$ & 2.383 & 2.504 \\
\hline M-N1 & & & & $2.005(5)$ & 2.029 & 2.030 & $2.015(4)$ & 2.058 & 2.228 \\
\hline $\mathrm{M}-\mathrm{N} 3$ & & & & $1.991(5)$ & 2.029 & 2.030 & $2.014(4)$ & 2.058 & 2.228 \\
\hline \multicolumn{10}{|l|}{ Bond angles $/^{\circ}$} \\
\hline \multicolumn{10}{|l|}{ Dihedral angle $/^{\circ}$} \\
\hline $\begin{array}{l}\text { C1N1C3C2N2/ } \\
\text { C6N3C7C8N4 }\end{array}$ & 48.91 & 61.31 & 76.21 & 69.03 & 66.97 & 64.80 & 71.15 & 64.97 & 61.53 \\
\hline
\end{tabular}

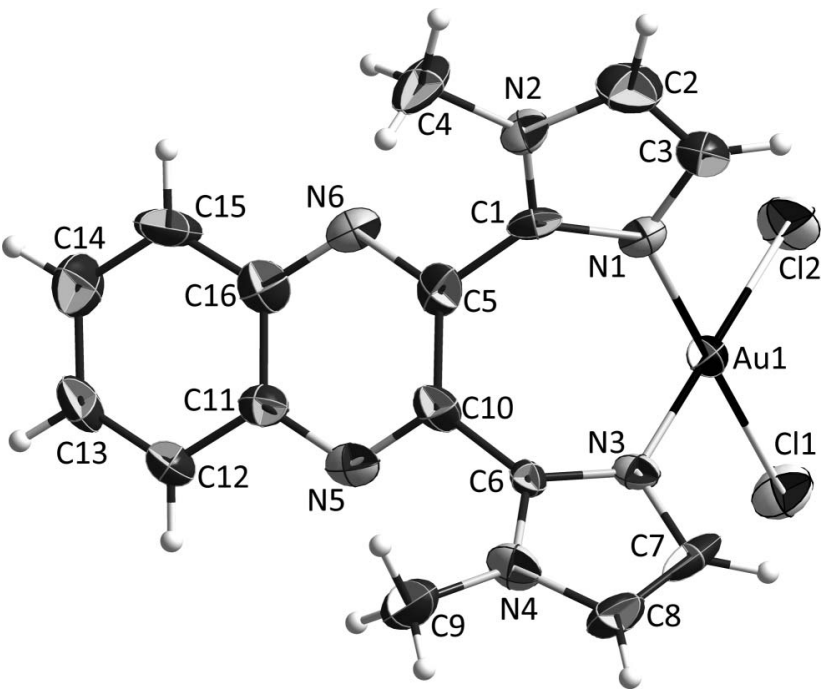

Fig. 3 The molecular structure of $\left[\mathrm{AuCl}_{2}(\mathrm{bmiq})\right]^{+}$in the crystal of $\left[\mathrm{AuCl}_{2}\right.$ (bmiq) $]\left[\mathrm{AuCl}_{4}\right]$ (ellipsoid probability: 95\%).

Although $\mathrm{PtCl}_{2}$ compounds in particular can be light emitting on excitation, ${ }^{10}$ the complex of bmiq was found to be nonluminescent in the solid or in $\mathrm{CH}_{2} \mathrm{Cl}_{2}$ solution, probably due to non-radiative decay involving the non-rigid methylimidazolyl functions. The compound $\left[\mathrm{AuCl}_{2}(\mathrm{bmiq})\right]\left(\mathrm{AuCl}_{4}\right)$ showed emission at $440 \mathrm{~nm}$ after excitation at $300 \mathrm{~nm}$ in dichloromethane.

\section{One-electron reduction}

The one-electron character of the primary reduction processes in the free ligand bmiq and in the complexes was checked coulometrically and, in the case of reversible steps, was confirmed by the nearly $60 \mathrm{mV}$ difference between the cathodic peak and
Table 3 Electrochemical data of compounds

\begin{tabular}{llll}
\hline compound & solvent $^{a}$ & $T / \mathrm{K}$ & redox potential $^{b}\left(\mathrm{~V} v s . \mathrm{Fc}^{+/ 0}\right)$ \\
\hline bmiq & $\mathrm{CH}_{2} \mathrm{Cl}_{2}$ & 293 & $-2.31[70]^{c}$ \\
{$\left[\mathrm{PtCl}_{2}(\right.$ bmiq $\left.)\right]$} & $\mathrm{CH}_{2} \mathrm{Cl}_{2}$ & 293 & $-1.62[80]^{c}$ \\
{$\left[\mathrm{AuCl}_{2}\right.$ (bmiq) $]\left[\mathrm{AuCl}_{4}\right]$} & $\mathrm{C}_{3} \mathrm{H}_{7} \mathrm{CN}$ & 203 & ${ }^{c}$
\end{tabular}

${ }^{a} 0.1 \mathrm{~mol} \mathrm{dm}^{-3} \mathrm{Bu}_{4} \mathrm{NPF}_{6}$ as electrolyte. ${ }^{b}$ Half-wave potentials measured at $100 \mathrm{mV} \mathrm{s}^{-1}$ scan rate; [peak potential differences $/ \mathrm{mV}{ }^{c} i_{\mathrm{pc}} / i_{\mathrm{pa}} \approx 1.0$. ${ }^{d}$ Irreversible reduction, interfering waves around $0.0 \mathrm{~V}$ from the two $\mathrm{Au}^{\mathrm{III}}$ species.

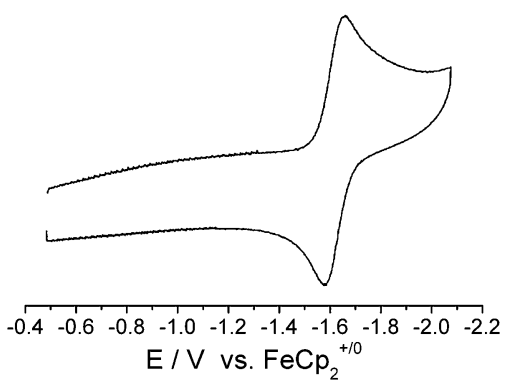

Fig. 4 The cyclic voltammogram of $\left[\mathrm{PtCl}_{2}(\mathrm{bmiq})\right]$ in $\mathrm{CH}_{2} \mathrm{Cl}_{2} / 0.1 \mathrm{~mol} \mathrm{dm}^{-3} \mathrm{Bu}_{4} \mathrm{NPF}_{6}\left(100 \mathrm{mV} \mathrm{s}^{-1}\right.$ scan rate $)$.

the anodic counter-peak in cyclic voltammetry (Fig. 4). Whereas bmiq and its $\mathrm{PtCl}_{2}$ complex could be reduced reversibly to the persistent radical anions bmiq ${ }^{--}$and $\left[\mathrm{PtCl}_{2}(\mathrm{bmiq})\right]^{--}$under ambient conditions, the gold(III) species $\left[\mathrm{AuCl}_{2}(\mathrm{bmiq})\right]\left(\mathrm{AuCl}_{4}\right)$ showed only irreversible electron uptake, even at $-70{ }^{\circ} \mathrm{C}$ in $n$ butyronitrile. The inability to detect an in situ EPR signal leaves the formation of a persistent species $\left[\mathrm{AuCl}_{2}(\mathrm{bmiq})\right]^{\cdot}$ in question. The complexes are more easily reduced than the free ligand (Table 3), in agreement with the changed structure and with the 


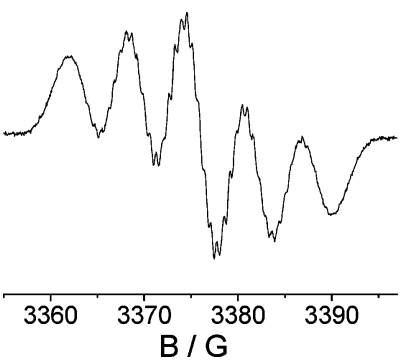

Fig. 5 ESR spectrum of bmiq-- obtained by reduction of bmiq with $\mathrm{K}$ in THF at $293 \mathrm{~K}$.

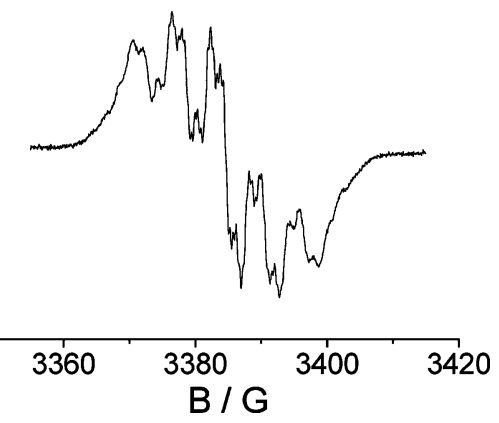

Fig. 6 ESR spectrum of electrochemically generated $\left[\mathrm{PtCl}_{2}(\mathrm{bmiq})\right]^{{ }^{-}}$at $293 \mathrm{~K}$ in $\mathrm{CH}_{2} \mathrm{Cl}_{2} / 0.1 \mathrm{~mol} \mathrm{dm}^{-3} \mathrm{Bu}_{4} \mathrm{NPF}_{6}$.

$\sigma$-acceptor functions of the dichlorometal fragments. Both bmiq ${ }^{\cdot-}$ and $\left[\mathrm{PtCl}_{2}\right.$ (bmiq)] ${ }^{--}$show hyperfine-split EPR signals (Fig. 5 and 6 ), the spectra being dominated by $1: 2: 3: 2: 1$ quintet coupling from two equivalent ${ }^{14} \mathrm{~N}$ atoms, of $6.2 \mathrm{G}$ and $6.0 \mathrm{G}$ for bmiq ${ }^{--}$and $\left[\mathrm{PtCl}_{2} \text { (bmiq) }\right]^{--}$, respectively $\left({ }^{195} \mathrm{Pt}\right.$ coupling estimated at $\left.\leq 10 \mathrm{G}\right)$. These values indicate ${ }^{22}$ spin concentration in the pyrazine ring of the quinoxaline part of the molecule, an assumption which is supported by DFT spin density calculations (Fig. 7 and 8) and also by the structural changes calculated for the radical anions bmiq ${ }^{--}$and $\left[\mathrm{PtCl}_{2} \text { (bmiq) }\right]^{{ }^{-}}$(Table 2). The major changes on reduction occur in the pyrazine ring, while the coordination is mainly affected by the added charge. It is concluded, therefore, that the electronic structure of bmiq and its complexes is similar to that of the corresponding dppz, bpq and Quinox-P ligands, i.e. the electron transfer site (quinoxaline) is spatially and electronically separated from the metal binding site $^{1 \mathrm{a}, 4}$ (here: the imidazole rings).

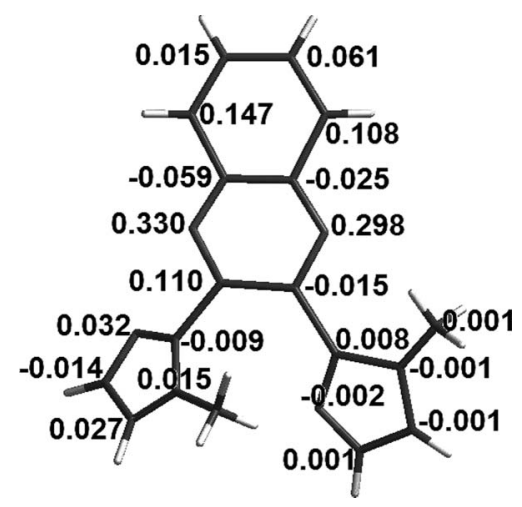

Fig. 7 DFT calculated spin densities for bmiq"-

Although some additional hyperfine splitting is visible in the EPR spectra (Fig. 5 and 6), the total number of theoretical lines

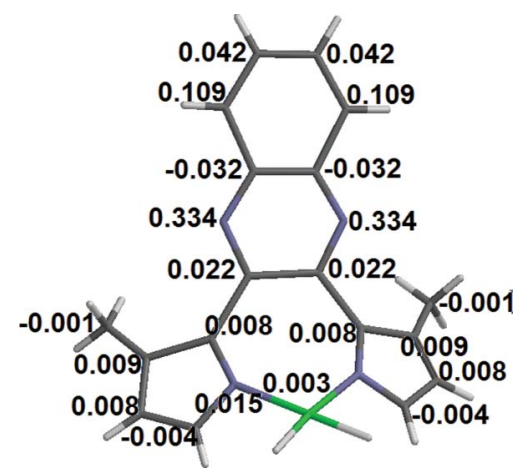

Fig. 8 DFT calculated spin densities for $\left[\mathrm{PtCl}_{2}(\mathrm{bmiq})\right]^{--}$.

(70 875) from 8 different nuclei $\left(5 \times{ }^{1} \mathrm{H}, 3 \times{ }^{14} \mathrm{~N}\right)$ in bmiq ${ }^{\cdot-}$ prevented us from further analysis and assignment of the smaller $(\leq 1 \mathrm{G})$ EPR coupling constants.

The isotropic $g$ values of bmiq $^{\cdot-}$ and $\left[\mathrm{PtCl}_{2}(\mathrm{bmiq})\right]^{\cdot-}$ differ only slightly (2.0034 and 2.0004), which confirms the hypothesis on the separation of spin localisation and metal binding. The dichloroplatinum(II) complexes of normal $\alpha$-diimines (where electron accommodation and coordination are not separated) show a much more pronounced shift of the isotropic $g$ and a considerable $g$ anisotropy. ${ }^{23}$

The inability to detect a neutral paramagnetic species $\left[\mathrm{AuCl}_{2} \text { (bmiq) }\right]^{\circ}$ by EPR could be due to its instability even at $-70{ }^{\circ} \mathrm{C}$ or to very rapid EPR relaxation with concomitant line broadening of a genuine gold(II) compound. True $\mathrm{Au}^{\mathrm{II}}$ compounds are still elusive even if several kinds of assumed gold(II) species with extensive spin delocalisation to $\mathrm{S}$ and similar donor ligands were reported. ${ }^{24}$ In agreement with these results, the DFT calculations predict considerable structural changes around the metal after reduction of $\left[\mathrm{AuCl}_{2} \text { (bmiq) }\right]^{+}$(Table 2).

The UV-vis spectroelectrochemical reduction of the neutral precursors to bmiq ${ }^{-}$and $\left[\mathrm{PtCl}_{2} \text { (bmiq) }\right]^{{ }^{-}}$is illustrated in Fig. 9 and 10 . The similarity confirms the comparable site of the electron addition, i.e. the quinoxaline part of bmiq, with its typical quinoxaline radical absorption of around $600 \mathrm{~nm} .{ }^{4,25}$

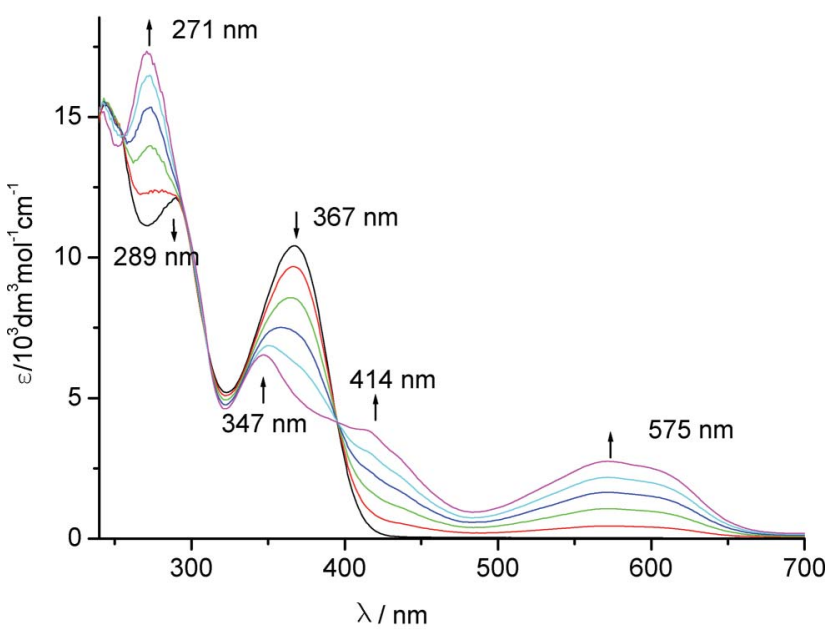

Fig. 9 UV-vis spectroelectrochemical monitoring of the reduction of bmiq in $\mathrm{CH}_{3} \mathrm{CN} / 0.1 \mathrm{~mol} \mathrm{dm}^{-3} \mathrm{Bu}_{4} \mathrm{NPF}_{6}$. 


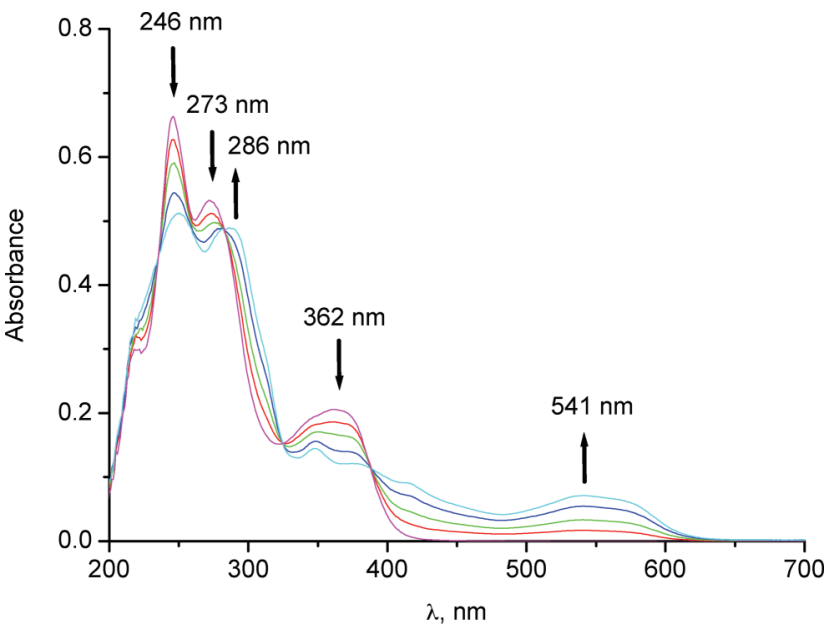

Fig. $10 \mathrm{UV}$-vis spectroelectrochemical reduction of $\left[\mathrm{PtCl}_{2}(\mathrm{bmiq})\right]$ in $\mathrm{CH}_{3} \mathrm{CN} / 0.1 \mathrm{~mol} \mathrm{dm}^{-3} \mathrm{Bu}_{4} \mathrm{NPF}_{6}$.

The distinct differences between the isoelectronic platinum(II) and gold(III) complexes are best explained using DFT calculated MO energies and diagrams (Table 4, Fig. 11). While the absolute energies are dependant on the (different) charges, the relative orbital ordering reveals a significant dichotomy: the positively charged gold system exhibits much more stabilised metal-based orbitals, leading to a LUMO involving mainly $\mathrm{Au}-\mathrm{Cl}$ and $\mathrm{Au}-$ $\mathrm{N} \sigma$ bonds. The occupation of such MOs generally causes chemical reactivity such as chloride dissociation. ${ }^{26}$ In contrast, the dichloroplatinum analogue has the unoccupied metal-chloride

Table 4 DFT calculated orbital energies of complexes

\begin{tabular}{lll}
\hline & \multicolumn{2}{l}{ Orbital energies $(\mathrm{DFT})$} \\
\cline { 2 - 3 } Orbitals & {$\left[\mathrm{PtCl}_{2}(\mathrm{bmiq})\right]$} & {$\left[\mathrm{AuCl}_{2}(\mathrm{bmiq})\right]^{+}$} \\
\hline$\pi^{*}$ & $-0.117,-0.088,-0.034$ & $-0.224,-0.202,-0.149$ \\
$\sigma^{*}(\mathrm{M}-\mathrm{Cl})$ & -0.028 & -0.263 \\
$\mathrm{HOMO}$ & -0.198 & -0.373 \\
\hline
\end{tabular}

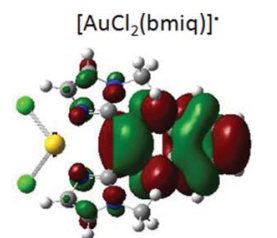

LUMO

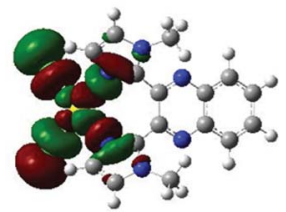

SOMO
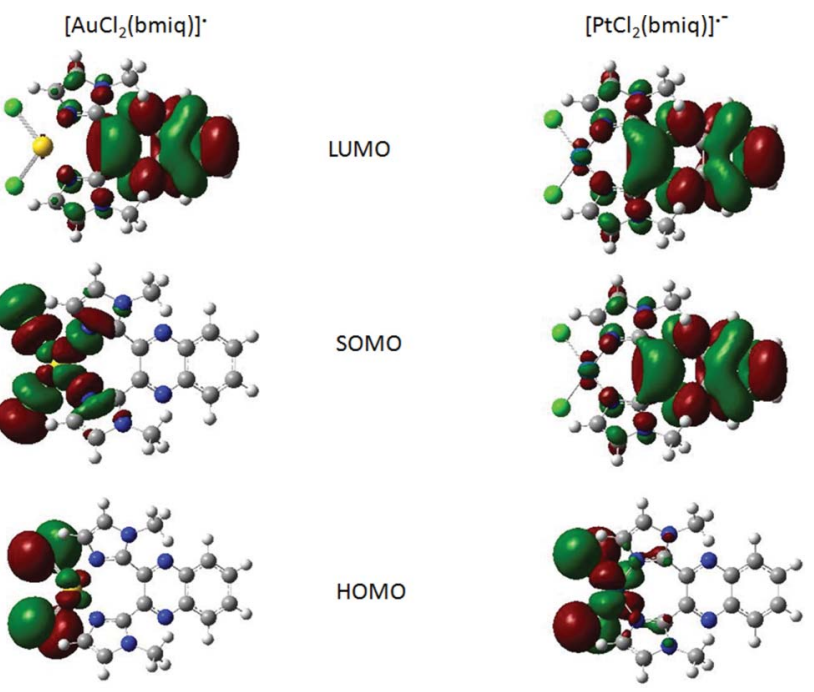

Fig. 11 The DFT-calculated frontier orbital representations of the one-electron reduced gold and platinum complexes. $\sigma$ bond orbitals lying above the bmiq ligand-located $\pi^{*}$ MOs (Table 4), which results in the observed reversible formation of a persistent anion radical complex.

Summarising, we could add a new member to the series (Scheme 1) of quinoxaline-based chelate ligands with separated metal binding and electron transfer sites. The ligand bmiq provides imidazole-imine $\mathrm{N}$ donors for coordination and could thus model the binding by two histidine side chains. Moreover, we could analyse the differences between the isoelectronic $\left[\mathrm{PtCl}_{2}\right]$ and $\left[\mathrm{AuCl}_{2}\right]^{+}$complexes experimentally (by cyclic voltammetry, EPR and UV-vis spectroelectrochemistry) and by DFT. The relative positioning of the unoccupied metal-chloride $v s$. ligand $\pi^{*}$ orbitals determines the presence or absence of reactivity on one-electron reduction of the $\left[\mathrm{MCl}_{2}(\mathrm{bmiq})\right]^{n}$.

\section{Acknowledgements}

This work was supported by Deutsche Forschungsgemeinschaft and Fonds der Chemischen Industrie.

\section{References}

1 (a) J. Fees, W. Kaim, M. Moscherosch, W. Matheis, J. Klima, M. Krejcik and S. Zalis, Inorg. Chem., 1993, 32, 166; (b) J. Fees, M. Ketterle, A. Klein, J. Fiedler and W. Kaim, J. Chem. Soc., Dalton Trans., 1999, 2595; (c) A. Klein, T. Scheiring and W. Kaim, Z. Anorg. Allg. Chem., 1999, 625, 1177; (d) P. J. Walsh, K. C. Gordon, N. J. Lundin and A. G. Blackman, J. Phys. Chem., 2005, 109, 5933; (e) S. L. Howell, K. C. Gordon, M. R. Waterland, K. H. Leung and D. L. Phillips, J. Phys. Chem. A, 2006, 110, 11194; $(f)$ W. Chen, C. Turro, L. A. Friedman, J. K. Barton and N. J. Turro, J. Phys. Chem. B, 1997, 101, 6995.

2 (a) J. C. Chambron, J. P. Sauvage, E. Amouyal and P. Koffi, New J. Chem., 1985, 9, 527; (b) F. Westerlund, F. Pierard, M. P. Eng, B. Nordén and P. Lincoln, J. Phys. Chem. B, 2005, 109, 17327; (c) N. Gupta, N. Grover, G. A. Neyhart, W. Liang, P. Singh and H. H. Thorp, Angew. Chem., 1992, 104, 1058, (Angew. Chem., Int. Ed. Engl., 1992, 31, 1048); (d) J. K. Barton, Science, 1986, 233, 727.

3 (a) T. Imamoto, K. Sugita and K. Yoshida, J. Am. Chem. Soc., 2005, 127, 11934; (b) T. Imamoto, A. Kumada and K. Yoshida, Chem. Lett., 2007, 36, 500 .

4 A. K. Das, E. Bulak, B. Sarkar, F. Lissner, Th. Schleid, M. Niemeyer, J. Fiedler and W. Kaim, Organometallics, 2008, 27, 218.

5 (a) S. E. Page, A. Flood and K. C. Gordon, J. Chem. Soc., Dalton Trans., 2002, 1180; (b) J. Granifo, M. E. Vargas, M. T. Garland and R. Baggio, Inorg. Chim. Acta, 2000, 305, 143; (c) J. Granifo, M. E. Vargas, H. Rocha, M. T. Garland and R. Baggio, Inorg. Chim. Acta, 2001, 321, 209; (d) M. A. Ivanov, G. O. Finagenova, M. V. Puzyk and K. P. Balashev, Opt. Spectrosc., 2006, 100, 367.

6 (a) A. Knödler, M. Wanner, J. Fiedler and W. Kaim, J. Chem. Soc., Dalton Trans., 2002, 3079; (b) O. Sarper, E. Bulak, W. Kaim and T. Varnali, THEOCHEM, 2006, 773, 35; (c) E. Bulak, M. Leboschka, B. Schwederski, O. Sarper, T. Varnali, J. Fiedler, F. Lisssner, Th. Schleid and W. Kaim, Inorg. Chem., 2007, 46, 5562.

7 I. Sóvágó, K. Várnagy and K. Ösz, Comments Inorg. Chem., 2002, 23, 149.

8 S. Abuskhuna, M. McCann, J. Briody, M. Devereux and V. McKee, Polyhedron, 2004, 23, 1731.

9 (a) B. Lippert, (ed.), Cisplatin, Wiley-VCH, Weinheim, 1999; (b) C. Mock, I. Puscasu, M. J. Rauterkus, G. Tallen, J. E. A. Wolff and B. Krebs, Inorg. Chim. Acta, 2001, 319, 109; (c) S. Roy, K. D. Hagen, D. P. U. Maheswari, M. Lutz, A. L. Spek, J. Reedijk and G. P. van Wezel, Chem. Med. Chem., 2008, 3, 1427.

10 (a) W. B. Connick, V. M. Miskowski, V. H. Houlding and H. B. Gray, Inorg. Chem., 2000, 39, 2585 and literature cited; (b) K. E. Dungey, B. D. Thompson, N. A. P. Kane-Maguire and L. L. Wright, Inorg. Chem., 2000, 39, 5192; (c) W. Kaim, A. Dogan, M. Wanner, A. Klein, I. Tiritiris, Th. Schleid, D. J. Stufkens, T. L. Snoeck, E. J. L. McInnes, J. Fiedler and S. Zalis, Inorg. Chem., 2002, 41, 4139. 
11 (a) M. Kato, Bull. Chem. Soc. Jpn., 2007, 80, 287; (b) R. McGuire, Jr., M. H. Wilson, J. J. Nash, P. E. Fanwick and D. R. McMillin, Inorg. Chem., 2008, 47, 2946; (c) C. Vogler, B. Schwederski, A. Klein and W. Kaim, J. Organomet. Chem., 1992, 436, 367; (d) M. Kato, S. Kishi, Y. Wakamatsu, Y. Sugi, Y. Osamura, T. Koshiyama and M. Hasegawa, Chem. Lett., 2005, 34, 1368; (e) M. Kato, A. Omura, A. Toshikawa, S. Kishi and Y. Sugimoto, Angew. Chem., 2002, 114, 3315, (Angew. Chem., Int. Ed., 2002, 41, 3183).

12 (a) P. Du, J. Schneider, F. Li, W. Zhao, U. Patel, F. N. Castellano and R. Eisenberg, J. Am. Chem. Soc., 2008, 130, 5056; (b) S. Rau, D. Walther and J. G. Vos, Dalton Trans., 2007, 915.

13 (a) W. B. Connick, R. E. Marsh, W. P. Schaefer and H. B. Gray, Inorg. Chem., 1997, 36, 913; (b) V. M. Textor and H. R. Oswald, Z. Anorg. Allg. Chem., 1974, 407, 244; (c) R. H. Herber, M. Croft, M. J. Coyer, B. Bilash and A. Sahiner, Inorg. Chem., 1994, 33, 2422; (d) W. B. Connick, L. M. Henling, R. E. Marsh and H. B. Gray, Inorg. Chem., 1996, 35, 6261.

14 (a) E. A. M. Geary, K. L. McCall, A. Turner, P. R. Murray, E. J. L. McInnes, L. A. Jack, L. J. Yellowlees and N. Robertson, Dalton Trans., 2008, 3701; (b) P. S. Braterman, J.-I. Song, C. Vogler and W. Kaim, Inorg. Chem., 1992, 31, 222; (c) W. Kaim and A. Klein, Organometallics, 1995, 14, 1176; (d) W. Kaim, B. Schwederski, A. Dogan, J. Fiedler, C. J. Kuehl and P. J. Stang, Inorg. Chem., 2002, 41, 4025.

15 (a) F. Basolo, and R. G. Pearson, Mechanisms of Inorganic Reactions, A Study of Metal Complexes in Solution, 2nd ed., Wiley, New York, 1967; (b) M. L. Tobe, and J. Burgess, Inorganic Reaction Mechanisms, Addison Wesly Longman, Harlow, England, 1999.

16 (a) R. A. Periana, D. J. Taube, S. Gamble, H. Taube, T. Satoh and H. Fujii, Science, 1998, 280, 560; (b) A. E. Shilov, and G. B. Shul'pin, Activation and Catalytic Reactions of Saturated Hydrocarbons, Kluwer, Dordrecht, 2000
17 (a) S. R. Seidel and P. J. Stang, Acc. Chem. Res., 2002, 35, 972; (b) W.-Y. Sun, M. Yoshizawa, T. Kusukawa and M. Fujita, Curr. Opin. Chem. Biol., 2002, 6, 757.

18 (a) M. Krejcik, M. Danek and F. Hartl, J. Electroanal. Chem., 1991, 317, 179; (b) W. Kaim, S. Ernst and V. Kasack, J. Am. Chem. Soc., 1990, $112,173$.

19 P. Anzenbacher, Jr., A. C. Try, H. Miyaji, K. Jursíková, V. M. Lynch, M. Marquez and J. L. Sessler, J. Am. Chem. Soc., 2000, 122, 10268.

20 G. M. Sheldrick, SHELXL-97, Program for refinement of crystal structures, University of Göttingen, Germany, 1997.

21 M. J. Frisch et al., Gaussian 98, Revision A.3, Gaussian, Inc., Pittsburgh, PA, 1998

22 W. Kaim, Chem. Ber., 1982, 115, 910.

23 (a) A. Dogan, B. Sarkar, A. Klein, F. Lissner, Th. Schleid, J. Fiedler, S. Záliš, V. K. Jain and W. Kaim, Inorg. Chem., 2004, 43, 5973; (b) W. Kaim, A. Dogan, M. Wanner, A. Klein, I. Tiritiris, T. Schleid, D. J. Stufkens, T. L. Snoeck, E. J. L. McInnes, J. Fiedler and S. Záliš, Inorg. Chem., 2002, 41, 4139; (c) A. Klein, S. Hasenzahl, W. Kaim and J. Fiedler, Organometallics, 1998, 17, 3532; (d) W. Kaim and A. Klein, Organometallics, 1995, 14, 1176.

24 (a) L. Ihlo, M. Kampf, R. Böttcher and R. Kirmse, Z. Naturforsch, 2002, 57b, 171; (b) M. Kampf, R.-M. Olk and R. Kirmse, Z. Anorg. Allg. Chem., 2002, 628, 34; (c) J. L. Shaw, J. Wolowska, D. Collison, J. A. K. Howard, E. J. L. McInnes, J. McMaster, A. J. Blake, C. Wilson and M. Schröder, J. Am. Chem. Soc., 2006, 128, 13827.

25 F. Hilgers, W. Kaim, A. Schulz and S. Záliš, J. Chem. Soc., Perkin Trans. 2, 1994, 135.

26 (a) W. Kaim, R. Reinhardt, E. Waldhör and J. Fiedler, J. Organomet. Chem., 1996, 524, 195; (b) W. Kaim, in New Trends in Molecular Electrochemistry, Hrsg. A. J. L. Pombeiro, Fontis Media, Lausanne, 2004, p. 127-151. 